\title{
The Kiss Switch Brings Inactive R3C Ligase Ribozyme Back to Life
}

\author{
Kana Tanizawa ${ }^{1}$, Sayuri Uchida ${ }^{1}$, Eri Kurihara ${ }^{1}$, Takuya Umehara ${ }^{1}$ and Koji Tamura ${ }^{1,2, *}$ \\ 1 Department of Biological Science and Technology, Tokyo University of Science, 6-3-1 Niijuku, Katsushika-ku, \\ Tokyo 125-8585, Japan; kanakana5629.pooh@icloud.com (K.T.); uchidasayuri@gmail.com (S.U.); \\ kurieri123@yahoo.co.jp (E.K.); tumehara@rs.noda.tus.ac.jp (T.U.) \\ 2 Research Institute for Science and Technology, Tokyo University of Science, 2641 Yamazaki, \\ Noda, Chiba 278-8510, Japan \\ * Correspondence: koji@rs.tus.ac.jp; Tel.: +81-3-5876-1472; Fax: +81-3-5876-1614
}

Received: 8 November 2017; Accepted: 5 January 2018; Published: 9 January 2018

\begin{abstract}
R3C ligase ribozyme catalyzes the nucleophilic attack by a $3^{\prime}$-hydroxyl on a $5^{\prime}$ - $\alpha$-phosphorus of triphosphates to form a $3^{\prime}-5^{\prime}$-phosphodiester bond. In the present study, although the truncation of $\mathrm{R} 3 \mathrm{C}$ ribozyme was accompanied by a large reduction in ligation activity (decrease by two orders of magnitude compared to that of the ligated product of full-length R3C ribozyme after $18.5 \mathrm{~h}$ at $23^{\circ} \mathrm{C}$ ), the introduction of complementary seven-membered kissing-loops served as a "switch" to reactivate the truncated $\mathrm{R} 3 \mathrm{C}$ ribozyme with approximately one-fifth of the activity of the full-length R3C ribozyme. This reactivation occurred in a trans-manner, and the grip region and substrate-binding site of the truncated R3C ribozyme were necessary to locate the substrate in the proper position for ligation with the other molecule. Reactivation resulted from complex tertiary interactions between two ribozymes, including kissing-loop interaction-induced annealing and the formation of a stable duplex. The drastic increase of the activity of poorly active ribozymes through the kissing-loop interaction may provide an important clue into the acquisition of substantial activity during the evolution of the RNA world.
\end{abstract}

Keywords: R3C ligase ribozyme; kissing-loop interaction; activity; RNA switch; RNA world

\section{Introduction}

The discovery of ribozymes [1,2] was an epoch-making event, resulting in a shift in the general concept of the understanding of life itself; RNA plays a dual role in information storage and catalysis, which has led to the "RNA world" hypothesis [3]. Several natural and artificial ribozymes catalyzing many steps of biological reactions have been identified to date. The ribozymes responsible for protein synthesis are particularly important because they might represent crucial molecules that contributed to the transition from an RNA world to an RNA/protein world [4-6]. However, before this transition, the nucleotides would have to be polymerized to certain threshold lengths so as to establish a functional RNA world. Joyce and Orgel suggest that a triple stem loop containing 40 to 60 nucleotides is the minimum required length for RNA catalytic activity [7].

Several RNA ligase ribozymes have been produced using in vitro selection techniques [8], such as class I ligase ribozyme [9], L1 ligase ribozyme [10], and R3C ligase ribozyme [11]. The R3C ribozyme is the smallest among them and was originally composed of 73 nucleotides [11], in which a three-way junction structure is formed around three stems (P2, P3, P4) (Figure 1). By partially deleting both the "grip" (P4 + P5) and "hammer" (P3) stem-loops, we generated a truncated R3C variant $(<\Delta 9-14$, GAAA, 35-39>, 50 nucleotides) which still retained greater than $10 \%$ activity of a full-length R3C ribozyme [12]. However, a single base-pair deletion from the "grip" region (< $<9-14$, GAAA,34-39>, 48 nucleotides) drastically decreased its activity to two orders of magnitude less than that of the ligated 
product of the full-length R3C ribozyme after $18.5 \mathrm{~h}$ at $23{ }^{\circ} \mathrm{C}$ (Figure 2) [12]. The acquisition of sufficient activity in ribozymes is considered to be a crucial step in the evolution of the RNA world. Here, we demonstrate that the inter-molecular interaction through the kissing-loop contributes to this dramatic increase in the ligation activity of this shortened R3C ribozyme with poor activity (Figure 2).

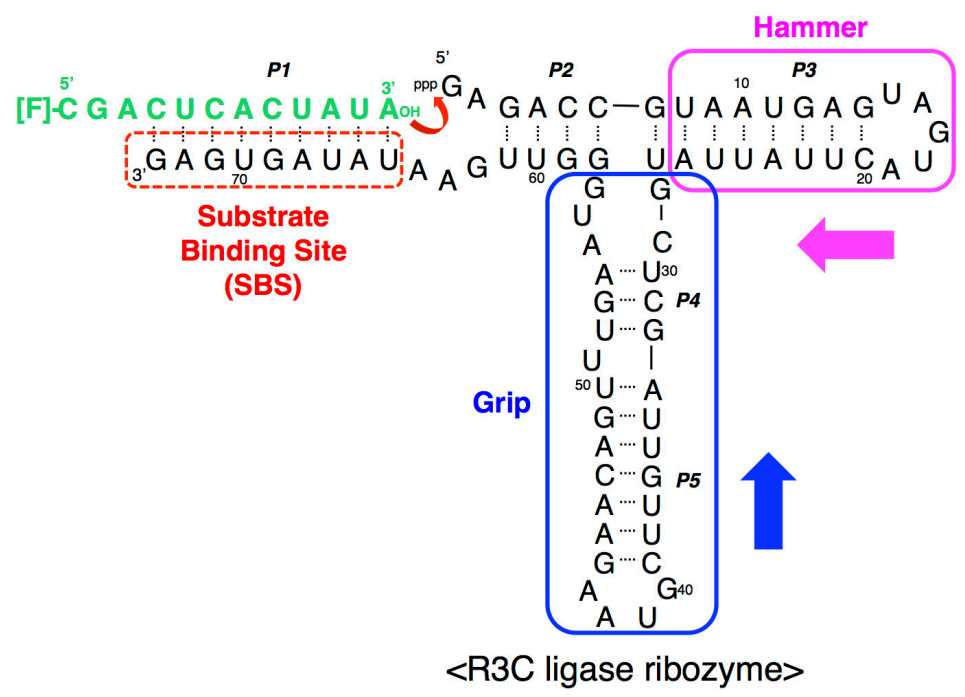

Figure 1. Composition of the R3C ligase ribozyme with a fluorescence-labeled RNA substrate. The ribozyme is composed of 73 nucleotides and forms five paired regions (P1-P5). The stem-loop region comprising P3 was designated as the "hammer", and the region comprising P4 and P5 was designated as the "grip" (see above). R3C ribozyme has a single-stranded substrate-binding site (SBS) at the $3^{\prime}$-terminal region. In a previous study [12], we created a smaller R3C variant ( 50 nucleotides) which still retained greater than $10 \%$ activity of full-length R3C by shortening both the "hammer" and "grip" [12]. The numbering of the nucleotides starts from the guanosine triphosphate at the $5^{\prime}$-end.

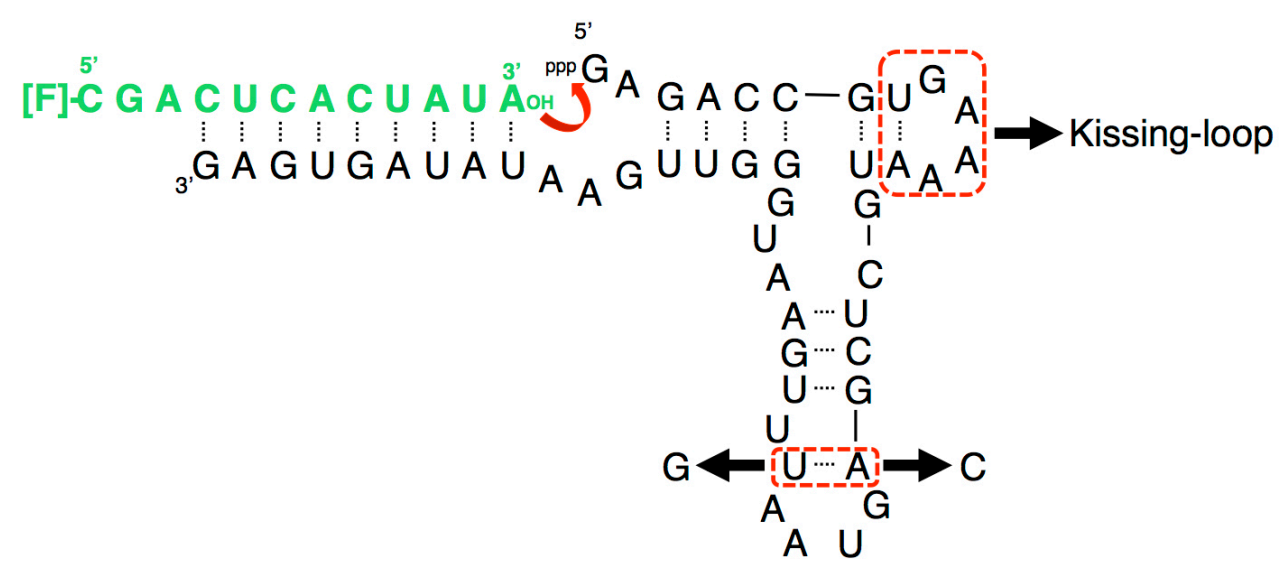

$<\triangle 9-14$, GAAA,34-39>

Figure 2. Composition of a variant of the R3C ligase ribozyme, $<\Delta 9-14$, GAAA,34-39 $>$, with a fluorescence-labeled RNA substrate [12]. Although the addition of only one more base pair to the "grip" region showed greater than 10\% activity of the full-length R3C $(<\Delta 9-14, \mathrm{GAAA}, 35-39>)$, $<\Delta 9-14$,GAAA,34-39> showed a drastic decrease of activity [12]. We introduced seven-membered single-stranded nucleotides, expecting the inter-molecular interaction through the kissing-loop, and replaced the A-U pair at the end of the grip stem with $\mathrm{C}-\mathrm{G}$. Because U51 is proximal to U50 of the A33-U50 pair, the A33-U51 pair can also be stacked on P4; however, this is not possible with the C-G pair (nucleotide position from Figure 1). 


\section{Materials and Methods}

\subsection{Plasmid Construction and In Vitro Transcription}

Unlabeled deoxyribonucleotides were synthesized by Eurofins Genomics K.K. (Tokyo, Japan). High-performance liquid chromatography-purified 5'-terminal 6-carboxyfluorescein (6-FAM)-labeled oligonucleotides were prepared by Japan Bio Services Co., Ltd. (Saitama, Japan). Each template DNA was prepared from chemically synthesized deoxyribonucleotides carrying the T7 promoter and the sequences corresponding to variants of the R3C ligase ribozyme, along with two synthetic primers for polymerase chain reaction amplification. RNA transcription was performed at $37{ }^{\circ} \mathrm{C}$ for $16 \mathrm{~h}$ or at $42{ }^{\circ} \mathrm{C}$ for $3 \mathrm{~h}$ in a reaction mixture containing $40 \mathrm{mM}$ Tris- $\mathrm{HCl}$ ( $\mathrm{pH} \mathrm{8.0),} 10 \mathrm{mM}$ dithiothreitol, $2 \mathrm{mM}$ spermidine, $8 \mathrm{mM} \mathrm{MgCl}_{2}, 2.5 \mathrm{mM}$ each nucleoside triphosphate (ATP, CTP, GTP, UTP), template DNA $(0.2 \mathrm{mg} / \mathrm{mL})$, and pure T7 RNA polymerase $(\sim 100 \mu \mathrm{g} / \mathrm{mL})$ [13]. The transcripts were purified by denaturing $12 \%$ polyacrylamide gel electrophoresis. The concentrations of the obtained purified RNA were determined from the ultraviolet absorbance at a wavelength of $260 \mathrm{~nm}$ using an Implen NanoPhotometer (München, Germany).

\subsection{Analysis of Ligation}

Ligation analysis was performed according to the method of Rogers and Joyce with a slight modification [11,12]. The R3C ligase ribozyme or its variants, dissolved in solution containing $50 \mathrm{mM}$ Tris- $\mathrm{HCl}\left(\mathrm{pH} \mathrm{8.5)}\right.$ and $15 \mathrm{mM} \mathrm{MgCl}_{2}$, were first heated to $37^{\circ} \mathrm{C}$ for $5 \mathrm{~min}$ and then cooled to $4{ }^{\circ} \mathrm{C}$. Then, the ligation reaction was started by adding $1.5 \mu \mathrm{L}$ of $50 \mu \mathrm{M}$ substrate to the solution. The final concentration of each ribozyme and the substrate was $5 \mu \mathrm{M}$ each. After incubation at $23{ }^{\circ} \mathrm{C}, 15 \mu \mathrm{L}$ of aliquots were removed at specific time points, put into the same volume of $7 \mathrm{M}$ urea and $0.08 \%(w / v)$ bromophenol blue, and stored at $-20{ }^{\circ} \mathrm{C}$ for quenching the reaction. The solution was then applied onto a denaturing $12 \%$ polyacrylamide gel for electrophoresis. The gel was analyzed on a Typhoon FLA 7000 system (GE Healthcare Japan, Tokyo, Japan), and the ligated products were quantified using Image Quant TL software. The measurements were obtained three times. Representative gel images were shown.

\subsection{Electrophoretic Mobility Shift Assay (EMSA)}

$<\mathrm{A}>$ or $<\mathrm{U}>(40 \mathrm{mM})$ or the mixture of $40 \mathrm{mM}$ each of $<\mathrm{A}>$ and $<\mathrm{U}>$ in $50 \mathrm{mM}$ Tris- $\mathrm{HCl}(\mathrm{pH} 8.5)$ and $15 \mathrm{mM} \mathrm{MgCl}$ was first heated to $37^{\circ} \mathrm{C}$ for $5 \mathrm{~min}$. Then, the solution was incubated at $23{ }^{\circ} \mathrm{C}$ for $18.5 \mathrm{~h}$. After the addition of an equal volume of $10 \%$ glycerol, the solution was analyzed by electrophoresis on non-denaturing 8\% polyacrylamide gels in $50 \mathrm{mM}$ Tris- $\mathrm{HCl}(\mathrm{pH} 8.5)$ and $15 \mathrm{mM}$ $\mathrm{MgCl}_{2}[13,14]$. The gel was stained with $0.04 \%$ toluidine blue.

\section{Results}

Our previous study indicated that a grip- and hammer-partially truncated mutant $(<\Delta 9-14$, GAAA,34-39>) retained slight ligation activity (Figure 2) [12]. Based on this less-active variant, in the present study we first prepared two new mutants, designated $<\mathrm{A}>$ and $<\mathrm{U}\rangle$, which possessed complementary seven-membered single-stranded nucleotides (5'-AAUAACA-3 ${ }^{\prime}$ and $5^{\prime}$-UGUUAUU-3 ${ }^{\prime}$ ) that replaced the original GAAA tetraloop and a U-A pair (Figures 2 and $3 a, b$ ). In addition, the A-U pair at the end of the grip-stem of the $<\Delta 9-14$, GAAA,34-39 $>$ (corresponding to the original position 33) [12] was replaced with $C-G$ (Figures 2 and $3 a, b)$ to stabilize the structure around the region.

The ligation activities of $<\mathrm{A}>$ or $<\mathrm{U}>$ alone were drastically decreased by two orders of magnitude, compared to that of the full-length $\mathrm{R} 3 \mathrm{C}$ ligase ribozyme, as evident from the data corresponding to the last time point (Figure $4,18.5 \mathrm{~h}$ ). This finding is concurrent with a previously reported conclusion that $<\Delta 9-14$, GAAA,34-39 $>$ showed low activity [12]. This means that the replacement of the GAAA tetraloop and a U-A pair with seven-membered single-stranded nucleotides did not apparently increase the ligation activities, i.e., slight activities were detected (Figure 4). However, surprisingly, 
as shown by the time course analysis of the ligation (Figure 4), the mixture of $<\mathrm{A}>$ and $<\mathrm{U}>$ drastically increased the ligation activity.
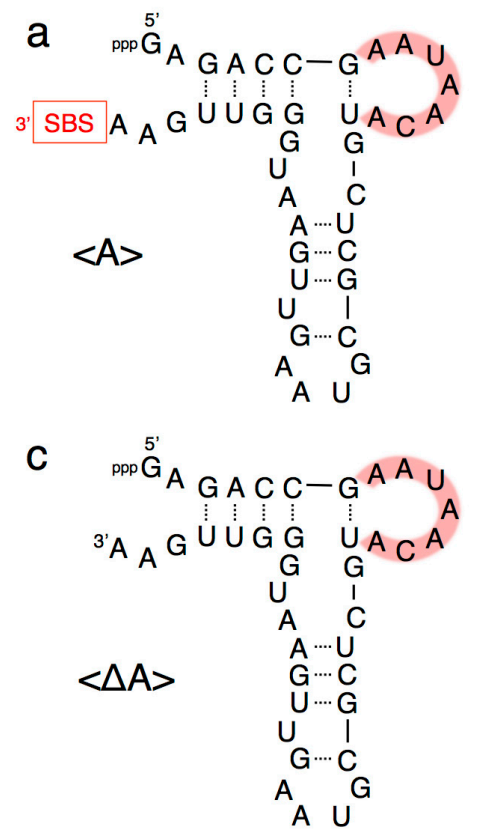
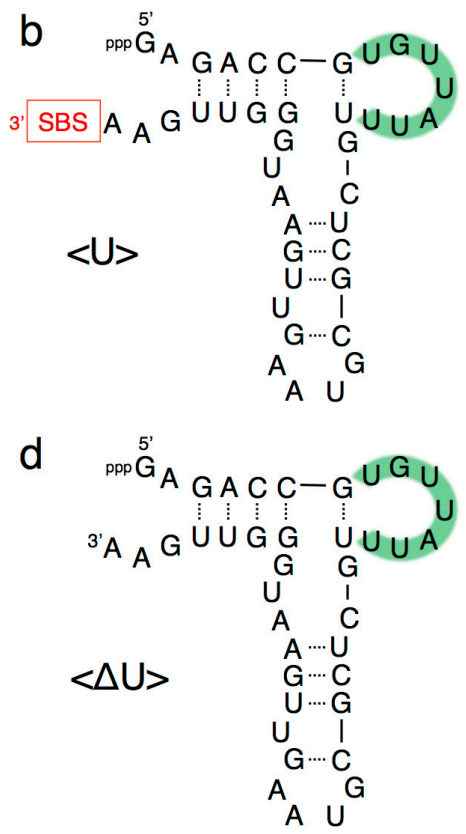

Figure 3. Composition of variants of R3C ligase ribozyme (a) $<\mathrm{A}>$, (b) $<\mathrm{U}\rangle$, (c) $<\Delta \mathrm{A}\rangle$, and (d) $<\Delta \mathrm{U}\rangle$ used in this study. Complementary seven-membered single stranded nucleotides (5'-AAUAACA-3' and $5^{\prime}$-UGUUAUU- $3^{\prime}$ ) are colored in pink and green, respectively. SBS, $3^{\prime}$-terminal substrate-binding site.

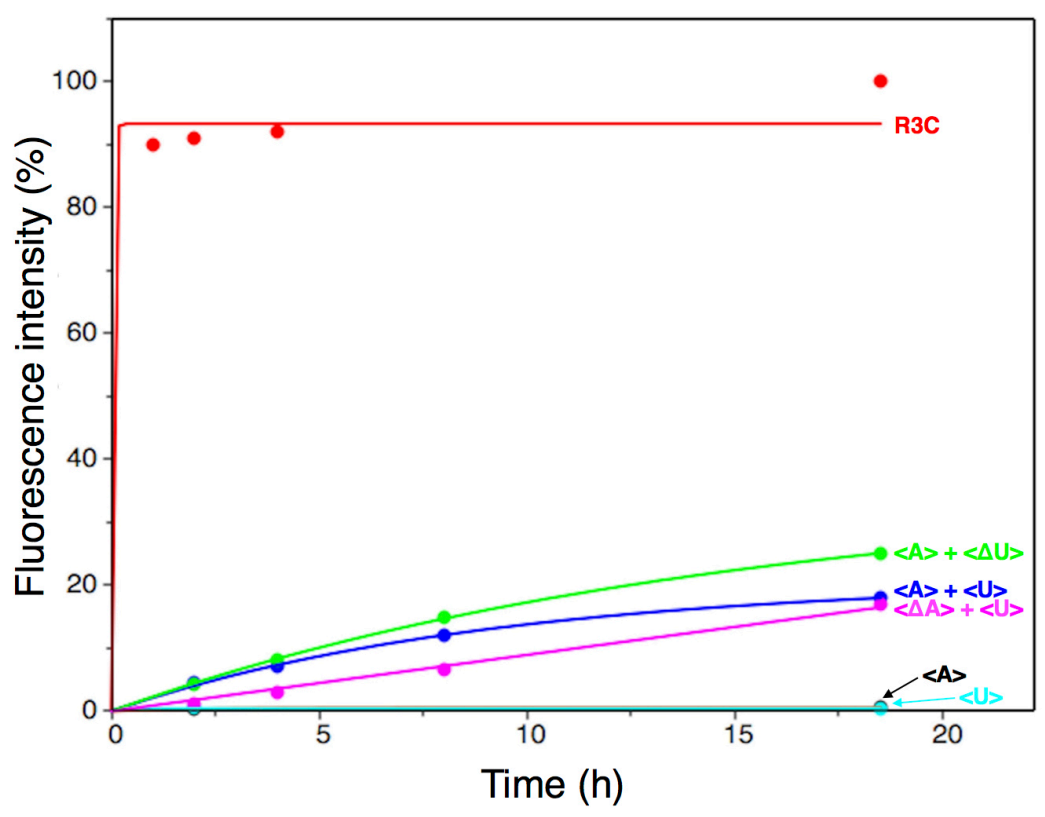

Figure 4. Analysis of the ligation product using a fluorescence-labeled RNA substrate (5'-CGACUCACUAUA- $3^{\prime}$ ) with a full-length R3C ligase ribozyme, or the combinations of $\langle\mathrm{A}\rangle,\langle\mathrm{U}\rangle$, $<\Delta \mathrm{A}>$, and $\left\langle\Delta \mathrm{U}>\right.$. After incubation at $23^{\circ} \mathrm{C}$ for the indicated times, $15-\mu \mathrm{L}$ aliquots were removed, put into the same volume of $7 \mathrm{M}$ urea and $0.08 \%(w / v)$ bromophenol blue, and stored at $-20{ }^{\circ} \mathrm{C}$ in order to quench the reaction. The solution was then applied to denaturing $12 \%$ polyacrylamide gel electrophoresis. The gel was visualized on Typhoon FLA 7000 (GE Healthcare Japan, Tokyo, Japan) and the ligated products were quantified using Image Quant TL software and plotted on the graph. The data were fit to a single exponential curve. 
Native gel electrophoresis indicated that the mixtures of $\langle\mathrm{A}>$ and $\langle\mathrm{U}>$ behaved as dimers by the introduction of complementary seven-membered kissing-loops (Figure 5a). In addition, when we used the RNA substrate possessing a 3'-deoxy adenosine at the 3'-terminal, the ligation activity was greatly decreased (Figure $5 \mathrm{~b}$ ), suggesting that the ligation site is $3^{\prime}-\mathrm{OH}$ and that the final product possesses $3^{\prime}-5^{\prime}$ linkage, as in the original R3C ribozyme [11,12].
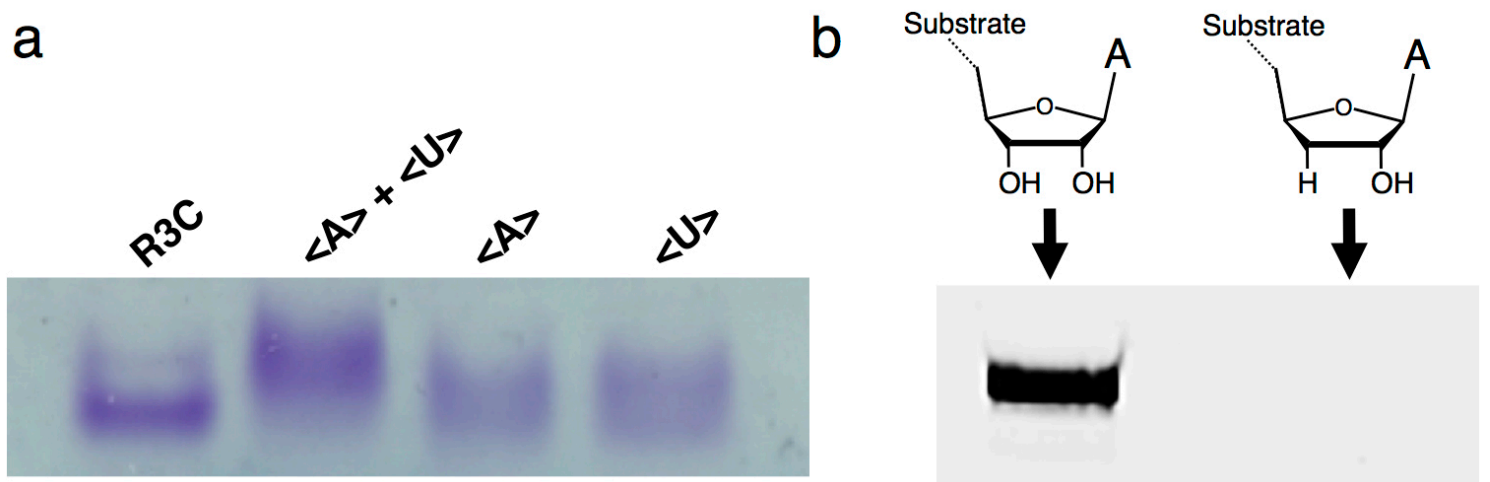

Figure 5. (a) Electrophoretic mobility shift assay of the (from left to right) full-length R3C ligase ribozyme, mixture of $\langle\mathrm{A}\rangle$ and $\langle\mathrm{U}\rangle,\langle\mathrm{A}\rangle$ alone, and $\langle\mathrm{U}\rangle$ alone. The nucleotides were separated via native $8 \%$ polyacrylamide gel electrophoresis. The gel was stained with $0.04 \%$ toluidine blue. (b) Analysis of the ligation product by the R3C ribozyme using an RNA substrate possessing $3^{\prime}$-deoxyadenosine at the $3^{\prime}$-terminal (5'-CGACUCACUAUA $\left(3^{\prime}\right.$-deoxy)- $\left.3^{\prime}\right)$. The volume of the reaction mixture was $15 \mu \mathrm{L}$ and the incubation was performed at $23^{\circ} \mathrm{C}$ for $18.5 \mathrm{~h}$. The gel was visualized on Typhoon FLA 7000 (GE Healthcare Japan, Tokyo, Japan).

As in the full-length R3C ligase ribozyme (composed of 73 nucleotides), $<\mathrm{A}>$ and $<\mathrm{U}>$ (Figure $3 a, b$ ) each possess a $3^{\prime}$ single-stranded structure at the site of substrate hybridization, i.e., the substrate-binding site (SBS) (Figure 1, P1 region). After deleting the SBS of $\langle\mathrm{A}\rangle$ or $\langle\mathrm{U}\rangle$ to generate two new variants designated $\langle\Delta \mathrm{A}\rangle$ and $\langle\Delta \mathrm{U}>$, respectively (Figure $3 \mathrm{c}, \mathrm{d}$ ), the mixture of $\langle\mathrm{A}\rangle$ and $\langle\Delta \mathrm{U}\rangle$, or that of $\langle\Delta \mathrm{A}\rangle$ and $\langle\mathrm{U}\rangle$, also showed similar activity to that observed with the mixture of $\langle\mathrm{A}\rangle$ and $\langle\mathrm{U}\rangle$, which was in contrast with the case of $\langle\mathrm{A}\rangle$ or $\langle\mathrm{U}\rangle$ alone (Figure 4 ). In addition, the ligation occurred on the SBS-null variants $(<\Delta \mathrm{A}>$ and $\langle\Delta \mathrm{U}\rangle)$, as evident from the size of the bands on the denaturing polyacrylamide gel electrophoresis (Figure 6).

We further generated two variants of R3C ribozyme with no "grip" (<hairpin-A $>$ and $<$ hairpin- $\Delta U>$ ) (Figure 7a,b). <hairpin-A > contained the SBS; however, <hairpin- $\Delta U>$ did not. Unexpectedly, the mixture of $\langle A>$ and $<$ hairpin- $\Delta U>$ caused 6-carboxyfluorescein (6-FAM)-labeled substrate ligation on $<$ hairpin- $\Delta U>$ despite the absence of SBS in this truncated molecule. However, the mixture of $<\Delta U>$ and $<$ hairpin-A $>$ did not yield any large ligation products (Figure 6).

We next designed $\left\langle\right.$ minihelix-A $>$ and $<$ minihelix-U $>$, which corresponded to a minihelix ${ }^{\text {Ala }}$ (a coaxial stack of the acceptor stem on the T-stem of E. coli tRNA ${ }^{\text {Ala }}$ ) [15-18]; however, the loop region were replaced with $5^{\prime}$-AAUAACA- $3^{\prime}$ and $5^{\prime}$-UGUUAUU- $3^{\prime}$, respectively (Figure 7c,d). The mixture of $<$ A $>$ and $<$ minihelix-U $>$ caused a drastic decrease of the ligation activity compared with that of the mixture of $\langle A\rangle$ and $\langle\Delta \mathrm{U}\rangle$, or the mixture of $\langle\mathrm{U}\rangle$ and $\langle\Delta \mathrm{A}\rangle$, and the level was comparable to that detected in the case of $<A>$ alone (Figure 6). Similar low activity was found in the case of the mixture of $<\mathrm{U}>$ and $<$ minihelix-A $>$ (Figure 6). 


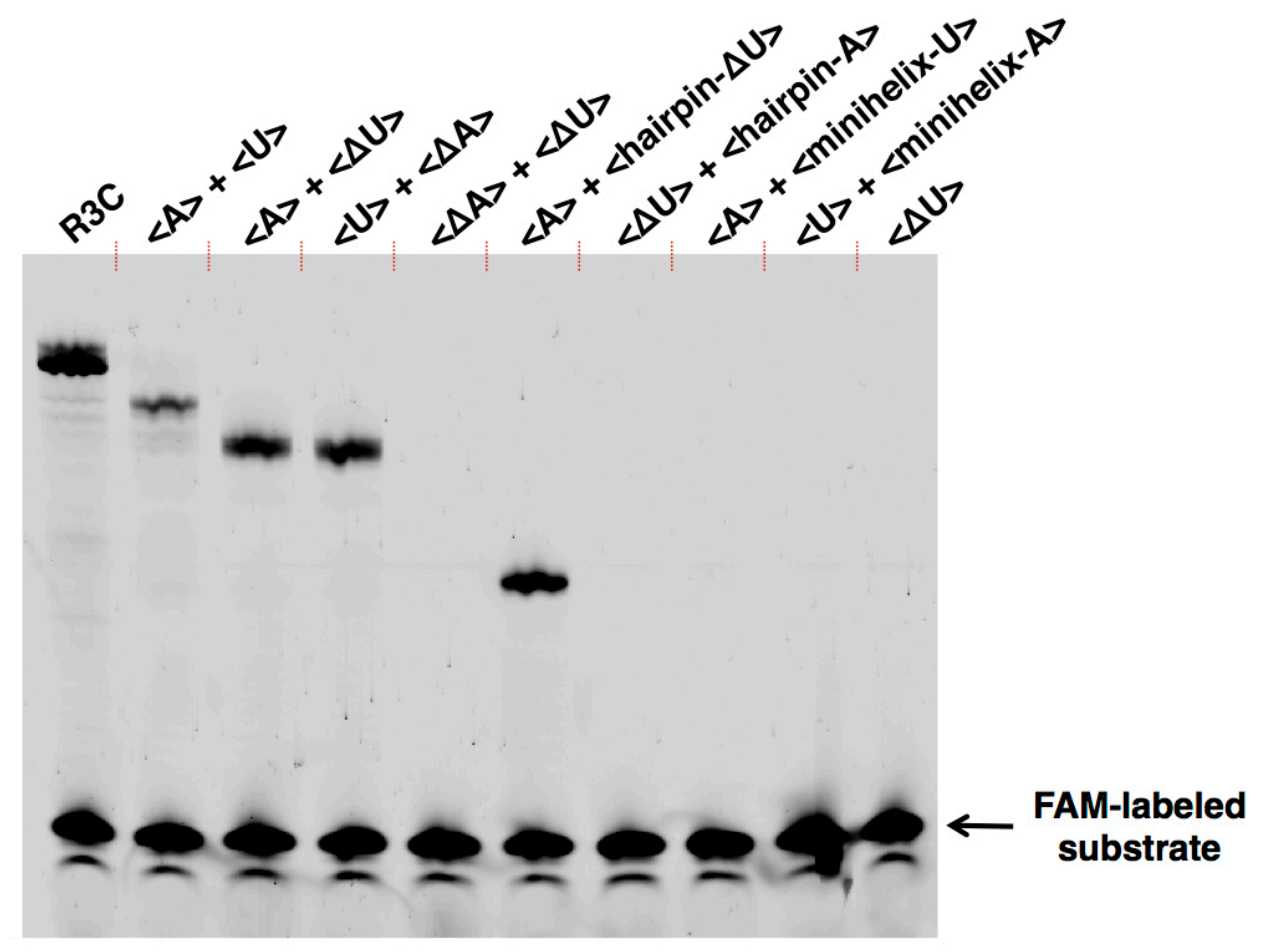

Figure 6. Ligation activities of the combinations of $\langle A\rangle,\langle U\rangle,\langle\Delta A\rangle,\langle\Delta U\rangle,\langle$ hairpin-A $\rangle$, $\langle$ hairpin- $\Delta U\rangle,\langle$ minihelix-A $>$, and $\langle$ minihelix-U $>$. The sequence of each RNA is described in Figures 1,3 , and 7 . The volume of the reaction mixture was $15 \mu \mathrm{L}$ and the incubation was performed at $23{ }^{\circ} \mathrm{C}$ for $18.5 \mathrm{~h}$. The solution was put into the same volume of $7 \mathrm{M}$ urea and $0.08 \%(w / v)$ bromophenol blue and then applied to denaturing $12 \%$ polyacrylamide gel electrophoresis. The gel was visualized on Typhoon FLA 7000 (GE Healthcare Japan, Tokyo, Japan).

a

$$
\begin{gathered}
{ }_{3 \cdot S B S A} A_{A} G \cup \cup G \text { G G } \\
<\text { hairpin- } A>
\end{gathered}
$$

C

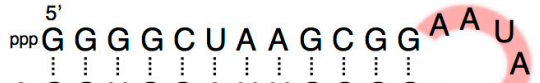
${ }_{3}^{A} C \mathrm{C} A C \mathrm{C} \cup \mathrm{CA} \cup \cup C G C \mathrm{CA}_{C} A$

$<$ minihelix-A $>$ b

$$
\begin{aligned}
& { }^{p p p} \stackrel{5}{\prime}_{A} \text { G A C C G } \cup G U \\
& { }^{3} A_{A} G \cup \cup G \cup \cup \cup A \\
& <\text { hairpin- } \Delta U>
\end{aligned}
$$

\section{d}

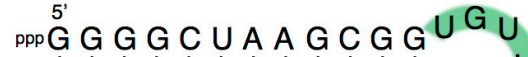

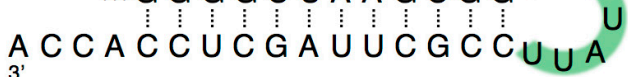
$<$ minihelix-U>

Figure 7. Composition of (a) <hairpin-A $>$, (b) $<$ hairpin- $\Delta U>$, (c) $<$ minihelix-A $>$, and (d) $<$ minihelix-U> Complementary seven-membered single stranded nucleotides (5'-AAUAACA-3 ${ }^{\prime}$ and $5^{\prime}$-UGUUAUU- $3^{\prime}$ ) are colored in pink and green, respectively. SBS, $3^{\prime}$-terminal substrate-binding site.

\section{Discussion}

The results of this study indicate that inter-molecular interactions caused by the introduction of the kissing-loop drastically increased the ligation activity of a truncated R3C ribozyme that showed poor activity previously (Figures 4 and 6). Our newly designed complementary seven-membered loops of $<\mathrm{A}>$ and $<\mathrm{U}>$ successfully formed dimers (Figure $5 \mathrm{a}$ ). The present results indicate that even if a truncated ribozyme retains slight activity, the activity can be drastically increased through simple mutual interactions. 
Importantly, the improvement of activity occurred in a trans-manner (Figures 6 and 8 ). The site of ligation was located at the $5^{\prime}$-end of the other ribozyme that was different from the substrate-bound ribozyme. This is evident from the combination of $<\mathrm{A}>$ and $<$ hairpin- $\Delta \mathrm{U}>$ yielding the ligation product (Figure 6). However, the combination $\langle\Delta \mathrm{U}\rangle$ and $<$ hairpin-A $>$ did not yield any large ligation products (Figure 6). These results suggest that the grip region and substrate-binding site of the truncated R3C ribozyme are necessary to locate the substrate in the proper position for ligation with the other molecule. Furthermore, the $5^{\prime}$-end and its vicinity are also important for the conformation of the site of ligation composed of both ribozymes. The success of $<$ hairpin- $\Delta U>$ and the failure of $<$ minihelix-U $>$ to rescue the activity of $<$ A $>$ suggested complex tertiary interactions between the two ribozymes, including kissing-loop interaction-induced annealing and the formation of a stable duplex (Figure 8). Human immunodeficiency virus type 1 (HIV-1) is known to form two types of dimers through kissing-loop-mediated interactions. In this case, interactions between the two loops initially generate unstable dimers; the formation of these dimers then induces annealing between the two stems to form stable intra-strand dimers [14,19-22]. A similar rearrangement may have occurred in our experimental system.

a

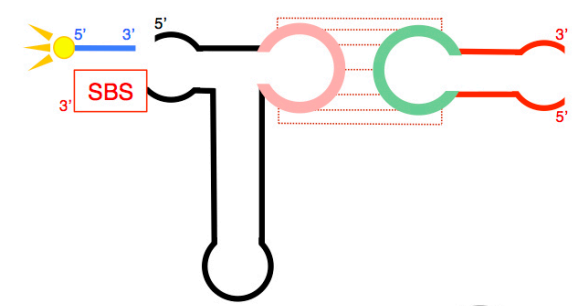

b

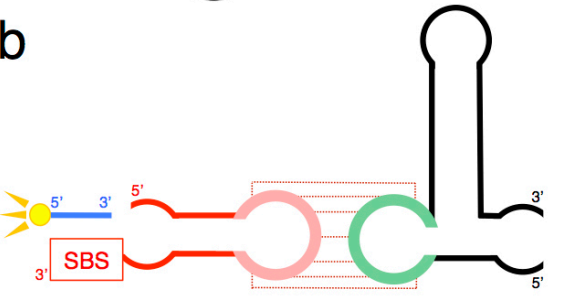

Ligation

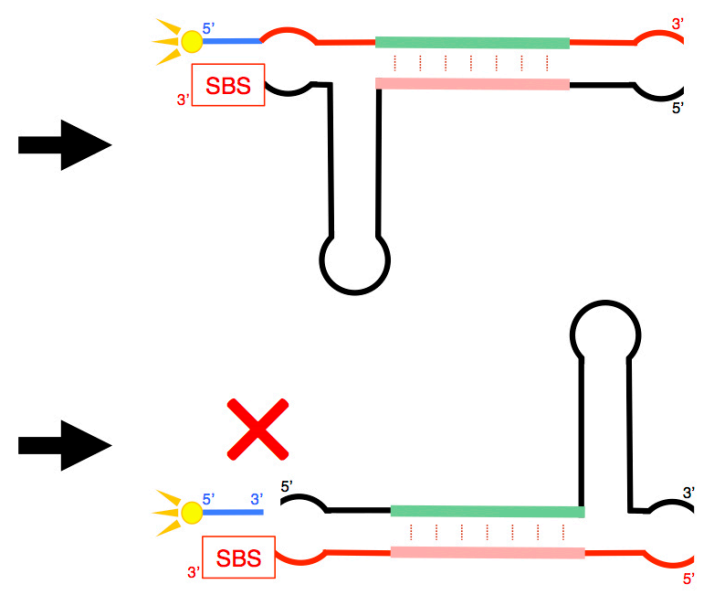

Figure 8. (a) Schematic representation of a process that may occur when $<A>$ and $<$ hairpin- $\Delta U\rangle$ combine. Although $<\mathrm{A}>$ contains the SBS, substrate ligation occurred on $<$ hairpin- $\Delta \mathrm{U}>$ despite the absence of SBS in this molecule (Figure 6). (b) Schematic representation of a process that may occur when $\langle\Delta U>$ and $<$ hairpin-A $>$ combine. Any large substrate ligation products were not detected in this combination, although $<$ hairpin-A $>$ contained the SBS (Figure 6 ). Both $(\mathbf{a}, \mathbf{b})$ suggest complex tertiary interactions between the two ribozymes, including kissing-loop interaction-induced annealing and the formation of a stable duplex, which partially rescued the activity of the truncated ribozyme.

The chemistry of the ligation catalyzed by R3C ribozyme is considered to be identical to that catalyzed by natural RNA and DNA polymerases [23,24]: a nucleophilic attack by a $3^{\prime}$-hydroxyl of the substrate on a $5^{\prime}$ - $\alpha$-phosphorus of guanosine triphosphates of the ribozyme to form a $3^{\prime}-5^{\prime}$-phosphodiester bond with the concomitant release of pyrophosphate. The proteinaceous enzymes use a two- $\mathrm{Mg}^{2+}$-ion mechanism: one $\mathrm{Mg}^{2+}$ lowers the $\mathrm{p} K_{\mathrm{a}}$ of the $3^{\prime}$-hydroxyl for the in-line nucleophilic attack, while the other $\mathrm{Mg}^{2+}$ assists in the pyrophosphate release by stabilizing the negative charge [25]. Kissing-loop interaction typically involves complete base pairing and continuous stacking of helices [26,27]. The base pairing through the loop regions of $\langle\mathrm{A}\rangle$ and $\langle\mathrm{U}\rangle$, with the effect of stacking, may make the deleted "hammer" region more "rigid", which could trigger the rearrangement of the complex and ensure the proper positioning of the reactants and $\mathrm{Mg}^{2+}$ ions.

The length of the nucleotides is a key factor for establishing the RNA world. We previously shortened the $\mathrm{R} 3 \mathrm{C}$ ribozyme up to $\sim 50$ nucleotides, which is the size formed by the catalytic functions 
of montmorillonite [28]. However, in general, primitive ribozymes, if they were formed, would have shown limited and weak activity; thus, the ability of such small-sized RNA to acquire improved activity would have been a crucial point in the formation of the primitive biological system based on the RNA world. Kissing-loop interaction is one of the typical RNA-RNA interactions. In addition to the example of HIV-1 described above [14,19-22], this interaction also occurs in the complex formed between ColE1 plasmid RNAs I and II [29]. Furthermore, a kissing-loop interaction between the substrate and the catalytic domain of the Varkud satellite ribozyme contributes to the rearrangement of the substrate helix into a conformation that is critical for substrate binding and activation [30]. In the substrate stem loop I (SLI)-stem loop V (SLV) kissing-loop junction of the ribozyme, SLV has been shown to act as a scaffold to provide stability to the junction and the $\mathrm{Mg}^{2+}$ ions associated with SLV [31]. Thus, the kissing-loop interaction may provide important clues into evolution of the RNA world. Structural analysis in the future will help to elucidate the details of the mechanism.

\section{Conclusions}

Introduction of complementary seven-membered kissing-loops served as a "switch" to reactivate the truncated $\mathrm{R} 3 \mathrm{C}$ ligase ribozyme with poor activity. This reactivation resulted from complex tertiary interactions between two ribozymes, including kissing-loop interaction-induced annealing and the formation of a stable duplex. The grip region and substrate-binding site of the truncated R3C ribozyme were necessary to locate the substrate in the proper position for ligation with the other molecule. Thus, the activity can be drastically increased through simple mutual interactions between small-sized RNAs and the kissing-loop interaction may provide a new perspective on the evolution of the RNA world.

Acknowledgments: We thank Yoshiya Ikawa (University of Toyama, Japan) for helpful discussions, and Tadashi Ando and Haruka Takano (both of Tokyo University of Science, Japan) for their support in the analysis of the ligation data. This work was supported by the Grants in Aid for Scientific Research from the Ministry of Education, Culture, Sports, Science and Technology (MEXT), Japan (Grant No. 17K19210 to KT).

Author Contributions: Kana Tanizawa, Sayuri Uchida, Eri Kurihara, Takuya Umehara, and Koji Tamura designed the experiments. Kana Tanizawa, Sayuri Uchida, and Eri Kurihara performed the experiments. All authors discussed the results and Koji Tamura wrote the manuscript. All authors approved the final manuscript.

Conflicts of Interest: The authors declare no conflict of interest.

\section{References}

1. Kruger, K.; Grabowski, P.J.; Zaug, A.J.; Sands, J.; Gottschling, D.E.; Cech, T.R. Self-splicing RNA: Autoexcision and autocyclization of the ribosomal RNA intervening sequence of Tetrahymena. Cell 1982, 31, 147-157. [CrossRef]

2. Guerrier-Takada, C.; Gardiner, K.; Marsh, T.; Pace, N.; Altman, S. The RNA moiety of ribonuclease P is the catalytic subunit of the enzyme. Cell 1983, 35, 849-857. [CrossRef]

3. Gilbert, W. Origin of life: The RNA world. Nature 1986, 319, 618. [CrossRef]

4. Illangasekare, M.; Sanchez, G.; Nickles, T.; Yarus, M. Aminoacyl-RNA synthesis catalyzed by an RNA. Science 1995, 267, 643-647. [CrossRef] [PubMed]

5. Kumar, R.K.; Yarus, M. RNA-catalyzed amino acid activation. Biochemistry 2001, 40, 6998-7004. [CrossRef] [PubMed]

6. Zhang, B.; Cech, T.R. Peptide bond formation by in vitro selected ribozymes. Nature 1997, 390, 96-100. [PubMed]

7. Joyce, G.F.; Orgel, L.E. Prospects for understanding the origin of the RNA world. In The RNA World; Gesteland, R.F., Atkins, J.F., Eds.; Cold Spring Harbor Laboratory Press: New York, NY, USA, 1999; pp. 1-25.

8. Joyce, G.F. Forty years of in vitro evolution. Angew. Chem. Int. Ed. Engl. 2007, 46, 6420-6436. [CrossRef] [PubMed]

9. Ekland, E.H.; Szostak, J.W.; Bartel, D.P. Structurally complex and highly active RNA ligases derived from random RNA sequences. Science 1995, 269, 364-370. [CrossRef] [PubMed] 
10. Robertson, M.P.; Ellington, A.D. In vitro selection of an allosteric ribozyme that transduces analytes to amplicons. Nat. Biotechnol. 1999, 17, 62-66. [CrossRef] [PubMed]

11. Rogers, J.; Joyce, G.F. The effect of cytidine on the structure and function of an RNA ligase ribozyme. RNA 2001, 7, 395-404. [CrossRef] [PubMed]

12. Kurihara, E.; Uchida, S.; Umehara, T.; Tamura, K. Development of a functionally minimized mutant of the R3C ligase ribozyme offers insight into the plausibility of the RNA world hypothesis. Biology 2014, 3, 452-465. [CrossRef] [PubMed]

13. Hamachi, K.; Hayashi, H.; Shimamura, M.; Yamaji, Y.; Kaneko, A.; Fujisawa, A.; Umehara, T.; Tamura, K. Glycols modulate terminator stem stability and ligand- dependency of a glycine riboswitch. BioSystems 2013, 113, 59-65. [CrossRef] [PubMed]

14. Takahashi, K.I.; Baba, S.; Chattopadhyay, P.; Koyanagi, Y.; Yamamoto, N.; Takaku, H.; Kawai, G. Structural requirement for the two-step dimerization of human immunodeficiency virus type 1 genome. RNA 2000, 6, 96-102. [CrossRef] [PubMed]

15. Schimmel, P.; Giegé, R.; Moras, D.; Yokoyama, S. An operational RNA code for amino acids and possible relationship to genetic code. Proc. Natl. Acad. Sci. USA 1993, 90, 8763-8768. [CrossRef] [PubMed]

16. Schimmel, P.; Ribas de Pouplana, L. Transfer RNA: From minihelix to genetic code. Cell 1995, 81, $983-986$. [CrossRef]

17. Tamura, K.; Schimmel, P. Chiral-selective aminoacylation of an RNA minihelix. Science 2004, $305,1253$. [CrossRef] [PubMed]

18. Tamura, K. Origins and early evolution of the tRNA molecule. Life 2015, 5, 1687-1699. [CrossRef] [PubMed]

19. Skripkin, E.; Paillart, J.C.; Marquet, R.; Ehresmann, B.; Ehresmann, C. Identification of the primary site of the human immunodeficiency virus type 1 RNA dimerization in vitro. Proc. Natl. Acad. Sci. USA 1994, 91, 4945-4949. [CrossRef] [PubMed]

20. Laughrea, M.; Jetté, L. A 19-nucleotide sequence upstream of the $5^{\prime}$ major splice donor is part of the dimerization domain of human immunodeficiency virus 1 genomic RNA. Biochemistry 1994, 33, 13464-13474. [CrossRef] [PubMed]

21. Laughrea, M.; Jetté, L. Kissing-loop model of HIV-1 genome dimerization: HIV-1 RNAs can assume alternative dimeric forms, and all sequences upstream or downstream of hairpin 248-271 are dispensable for dimer formation. Biochemistry 1996, 35, 1589-1598. [CrossRef] [PubMed]

22. Brunel, C.; Marquet, R.; Romby, P.; Ehresmann, C. RNA loop-loop interactions as dynamic functional motifs. Biochimie 2002, 84, 925-944. [CrossRef]

23. Steitz, T.A. A mechanism for all polymerases. Nature 1998, 391, 231-232. [CrossRef] [PubMed]

24. Sträter, N.; Lipscomb, W.N.; Klabunde, T.; Krebs, B. Two-metal ion catalysis in enzymatic acyl-and phosphoryl-transfer reactions. Angew. Chem. Int. Ed. Engl. 1996, 35, 2024-2055. [CrossRef]

25. Castro, C.; Smidansky, E.D.; Arnold, J.J.; Maksimchuk, K.R.; Moustafa, I.; Uchida, A.; Götte, M.; Konigsberg, W.; Cameron, C.E. Nucleic acid polymerases use a general acid for nucleotidyl transfer. Nat. Struct. Mol. Biol. 2009, 16, 212-218. [CrossRef] [PubMed]

26. Lee, A.J.; Crothers, D.M. Mechanism of codon recognition by transfer RNA studied with oligonucleotides larger than triplets. Structure 1998, 6, 993-1005. [CrossRef]

27. Scarabino, D.; Crisari, A.; Lorenzini, S.; Williams, K.; Tocchini-Valentini, G.P. tRNA prefers to kiss. EMBO J. 1999, 18, 4571-4578. [CrossRef] [PubMed]

28. Ferris, J.P. Montmorillonite-catalysed formation of RNA oligomers: The possible role of catalysis in the origins of life. Philos. Trans. R. Soc. B 2006, 361, 1777-1786. [CrossRef] [PubMed]

29. Eguchi, Y.; Tomizawa, J. Complexes formed by complementary RNA stem-loops. Their formations, structures and interaction with ColE1 Rom protein. J. Mol. Biol. 1991, 220, 831-842. [CrossRef]

30. DasGupta, S.; Suslov, N.B.; Piccirilli, J.A. Structural basis for substrate helix remodeling and cleavage loop activation in the Varkud satellite ribozyme. J. Am. Chem. Soc. 2017, 139, 9591-9597. [CrossRef] [PubMed]

31. Bergonzo, C.; Cheatham, T.E., III. $\mathrm{Mg}^{2+}$ binding promotes SLV as a scaffold in Varkud satellite ribozyme SLI-SLV kissing loop junction. Biophys. J. 2017, 113, 313-320. [CrossRef] [PubMed]

(C) 2018 by the authors. Licensee MDPI, Basel, Switzerland. This article is an open access article distributed under the terms and conditions of the Creative Commons Attribution (CC BY) license (http:/ / creativecommons.org/licenses/by/4.0/). 